\title{
Loss or Gain? The Role of Message Framing in Hotel Guests' Recycling Behaviour
}

\section{Laura Grazzini ${ }^{a 1}$, Padmali Rodrigo ${ }^{b}$, Gaetano Aiello ${ }^{a}$ and Giampaolo Viglia $^{b}$}

${ }^{a}$ University of Florence, Department of Economics and Management, Via delle Pandette 9, 50127, Firenze, Italy.

${ }^{b}$ University of Portsmouth, Department of Marketing and Sales, Portland Street, PO13DE, Portsmouth, United Kingdom.

${ }^{1}$ Email: laura.grazzini@unifi.it; corresponding author

Laura Grazzini is Research Fellow in Marketing at the Department of Economics and Management, University of Florence, Italy. Her research interests lie in the areas of consumer behavior, sustainable consumption, and experimental research.

Padmali Rodrigo is a Research Fellow in Marketing and Sales at University of Portsmouth (UoP) UK. Prior to joining UoP, she was an associate lecturer at the Newcastle Business School, Faculty of Business and Law, Northumbria University. Her research interests are in international consumer behavior, travel \& tourism, SME development and emerging markets.

Gaetano Aiello is Full Professor in Marketing at the at the Department of Economics and Management, University of Florence, Italy. His research interests lie in the areas of consumer behavior and strategic marketing. His work has been published in a number of international journals, such as Journal of Business Research and Psychology \& Marketing, among others.

Giampaolo Viglia is Reader in Marketing at the University of Portsmouth, UK. His research interests lie in the areas of pricing, consumer decision-making and online reputation. His work has been published in a number of international journals, such as Tourism Management, Journal of Business Research, International Journal of Hospitality Management and Psychology \& Marketing. 


\section{Loss or Gain? The Role of Message Framing in Hotel Guests' Recycling Behaviour}

One of the major challenges for the tourism sector is enacting sustainable behaviours. A key strategy for hoteliers is developing persuasive messages, with the goal of encouraging guests' voluntary participation in green programs. Through the lens of Prospect Theory and Construal Level Theory, the present study investigates to what extent a loss or gain-framed message influences recycling of hotel guests via a field and a lab experiment. The field experiment tests the moderating effect of message construal level (concrete or abstract) on the message frame that activate pro-environmental behaviour, while the laboratory study delves further into the mechanism by showing that perceived self-efficacy is the mechanism behind the activation of these behaviours. The findings from both studies suggest that hotel guests are more likely to engage in recycling behaviour when a concrete message is paired with a loss-framed message, because of a greater perceived self-efficacy. These results help to understand the theoretical psychological mechanisms and offer managerial implications for operators on how to engage guests to be active partners in sustainable tourism behaviours.

Keywords: message framing; construal level theory; field experiment; selfefficacy; recycling behaviour; sustainable tourism 


\section{Introduction}

There is an increasing concern about the impact of tourism sector on the environment (Dwyer, Forsyth, Spurr, \& Hoque, 2010; Font \& McCabe, 2017; Gössling \& Peeters, 2015; Lee, Jan, \& Yang, 2013). In this regard, particular attention has been devoted to hotel systems that consume a considerable amount of resources, seriously damaging the environment in daily operations (Han \& Yoon, 2015). The tourism sector contributes to the $6.7 \%$ of total waste generation in the EU-27, producing approximately 35 million tonnes of solid waste per year globally (Styles, Schönberger, \& Martos 2013). Therefore, waste management is a key issue within the hotel industry. For instance, in United Kingdom hotels produce around 290,000 tonnes of waste per year with an estimated cost of $£ 318$ million (WRAP 2015). Although $52 \%$ of all waste is recycled (WRAP 2017), enhancing recycling rates, which would reduce disposal costs and save natural resources, is a major challenge for this sector. By recycling, just in the UK the sector would be saving 113,000 tonnes of greenhouse gases (GHG) emissions (CO2) every year, with a cost saving benefit between $£ 1,790$ and $£ 1,801$ per tonne (WRAP 2011). Moreover, this would save a grand total of over 700 thousand GBP per year.

Research on environment-friendly behaviours has emerged as significant area of interest (Buckley, 2012; Miller, Merrilees \& Coghlan, 2015; Myung, McClaren, \& Li, 2012). Literature has recognized the importance of encouraging sustainable tourists' behaviours (i.e., those behaviour which does not negatively impact the natural environment - or may even benefit the environment; Juvan \& Dolnicar, 2016, p.31) as one of the major challenges for the sector (Chen \& Peng, 2012; Han \& Yoon, 2015; Kim \& Han, 2010). Therefore, for hoteliers, minimizing environmental harm is becoming essential to maintain competitiveness or to obtain a competitive advantage. 
This is particularly true when considering that on average, hotels generate approximately one kg of unsorted waste per guest per night (Styles et al. 2013), equating to 66 tonnes per hotel per year in the UK (WRAP 2011). However, hotels face a range of barriers to recycling because of guests' behaviours.

A key priority for hoteliers is finding ways to engage tourists to be active partners in sustainable behaviours (Warren, Becken, \& Coghlan, 2016). It has been found that the way environmental messages are presented or framed has a significant ability to persuade tourists' sustainable behaviours (Hardeman, Font \& Nawijn, 2017) and enhance their willingness to participate in pro-environmental programs (Dolnicar, Cvelbar \& Grün, 2017; Goldstein, Cialdini, \& Griskevicius, 2008; Lee \& Oh, 2014; Villarino \& Font, 2015). However, it has been argued that "the potential for tourism businesses to improve the persuasiveness of their sustainability communications is still largely unexplored" (Villarino \& Font, 2015, p. 333).

The aim of the present study is therefore to investigate new message appeals that might trigger tourists' pro-environmental behaviours. Specifically drawing from Prospect Theory and Construal Level Theory, the study investigates the effectiveness of a loss versus gain message framing in persuading hotel guests to engage in recycling behaviour. The study also tests the moderating effect of construal level and it proposes perceived self-efficacy as mediator of this interaction. Methodologically, the package of studies includes a field and laboratory experiment.

The present study proposes for the first time empirical validation for social science theories in a sustainable behaviour context and offers actionable indications from a managerial perspective. 


\section{Literature Review}

\section{Environmentally Sustainable Tourist Behaviour}

Research on environment-friendly behaviours is receiving growing attention in the tourism field (Miller et al., 2015; Myung et al., 2012) because of its increased negative impact on the environment. Specifically, environmentally sustainable tourist behaviour has been defined as "the tourist behaviour which does not negatively impact the natural environment (or may even benefit the environment) both globally and at the destination” (Juvan \& Dolnicar, 2016, p.31). In this regard, tourism literature has widely investigated how to favour pro-environmental behaviours. For instance, tourists can keep their environmental footprint low by buying environmentally labelled products (Esparon, Gyuris \& Stoeckl, 2013), choosing sustainable modes of transport (Dickinson, Robbins, \& Lumsdon, 2011; Hergesell \& Dickinger, 2013; Prillwitz \& Barr, 2012) and selecting green hotels along with sustainable destinations (Chen \& Tung, 2014; Han, Hsu, \& Sheu, 2010). Additionally, tourists can preserve environmental resources by avoiding waste. Previous research has explored how to save on water and energy waste (Chan \& Lam, 2003; Dolnicar et al., 2017), recycling waste (Radwan, Jones \& Minoli, 2012; Shanklin, Petrillose \& Pettay, 1991), and reusing hotel towels (Cvelbar, Grün \& Dolnicar, 2017; Goldstein et al., 2008; Mair \& Bergin-Seers, 2010).

Understanding the factors that affect pro-environmental behaviour is still at a moot point (Miller et al., 2015), especially in the tourism context where behaviours are largely influenced by habits and by the purpose of the holiday and travel motivations (Dolnicar \& Grün, 2009). Previous literature has identified two dominant causes for pro-environmental behaviour: self-interest and self-concept (Bolderdijk, Gorsira, Keizer \& Steg, 2013; Lindenberg \& Steg, 2007). Self-interest motives aim at maximizing 
personal utility so that people are willing to change their behaviour in return of personal benefits (Dolnicar et al. 2017). According to this theory, consumers are more likely to engage in pro-environmental actions when the request for help is accompanied by some tangible benefits to the self (White \& Simpson, 2013). On the contrary, a positive selfconcept relates to individual moral norms and to feeling good about oneself when doing good (Sachdeva, Iliev \& Medin, 2009). In this regard, studies have been emphasizing that leveraging a positive self-concept can trigger pro-environmental behaviour (Bolderdijk et al., 2013; Dolnicar et al., 2017; Van der Linden, 2015). The theoretical basis is that most people desire a stable, competent and morally good self-concept, and strive for consistency between their behaviour and this self-concept (Dunning, 2007). Therefore, acting green is considered to exert a positive influence on the self-concept (Bolderdijk et al., 2013; Mazar \& Zhong, 2010), allowing people to feel good.

Generally, researchers who view individuals' environmentally responsible behaviours as being stimulated by self-concept motives utilize the Norm Activation Model (NAM; Schwartz, 1977; Schwartz \& Howard, 1981). This model is based on the role of moral concerns and on trading-off personal benefit for environmental conservation (Bamberg \& Möser 2007). In the tourism literature, several scholars have adopted this position, showing a relationship between moral obligations and tourists' environmentally responsible behaviours (i.e., choosing eco-friendly travel options; Brown et al., 2010; Mehmetoglu, 2010). On the contrary, researchers who consider ecofriendly behaviours as self-interest motives mostly rely on rational-choice models such as the Theory of Reasoned Action (TRA) (Fishbein \& Ajzen, 1975) or Theory of Planned Behaviour (TPB) (Ajzen, 1991). Here, sustainable actions result from a rational evaluation of its costs and benefits (e.g., time, money, effort, and social approval; Abrahamse \& Steg, 2009; Egea \& Frutos, 2013). TRA and TPB underpin many relevant 
studies in tourism. They have been used for investigating intentions to select ecofriendly restaurants (Kim, Njite \& Hancer, 2013) and intentions to choose green hotels (Chen \& Tung, 2014; Han, Hsu \& Sheu, 2010), among many others.

Stern (2000), in his Value-Belief-Norm (VBN) Theory of Environmentalism, extended TRA, TPB, and NAM arguing that environmental behaviour can be triggered by various reasons including moral norms, money saving, or desire for comfort or freedom (Dolnicar et al. 2017). Compared to previous models, VBN has been less adopted in tourism (Kiatkawsin \& Han, 2017; Landon, Woosnam \& Boley, 2018).

Despite a growing interest on understanding what drives tourists' proenvironmental behaviours, a main limitation is that most studies have used self-reported past behaviour or behavioural intentions as their key variable of interest (Cvelbar et al., 2017). Only few studies have investigated actual behaviour (Dolnicar et al., 2017; Cvelbar et al., 2017; Goldstein et al., 2008; Mair \& Bergin-Seers, 2010), supporting the conclusion by Dolnicar and Ring (2014) that "studies that measure real behaviour are notably absent” (p. 43). In addition, as recently reported by Juvan and Dolnicar (2016) there is urgent need to measure actual behaviour in "recycling, picking up litter, reusing towels and similar” (p.36).

Even though customers show positive attitude towards green or sustainable practices both when at home and away (Kormos \& Gifford, 2014), a few actually act accordingly (Juvan \& Dolnicar, 2014; Miao \& Wei, 2013; Susskind, 2014). This discrepancy depends on the well-documented attitude-behaviour gap defined as "the differences between what people say and what people do" (Blake, 1999, p.275). Specifically, it has been argued that values, beliefs, attitudes and intentions are critical for understanding tourists' pro-environmental behaviours but are not sufficient in predicting them (Juvan \& Dolnicar, 2016). Moreover, as Miller (2003) points out, " $a$ 
weakness of much of this research is the distinction between what survey respondents say and what they actually ask for or do" (p. 19). In the same vein, Oates and McDonald (2014) state that "asking about attitudes or intentions to act in a green manner does not necessarily tell us very much about behaviour” (p.170).

Among the causes for this gap, there is the social desirability bias (Juvan \& Dolnicar, 2016; Karlsson \& Dolnicar, 2016). In sum, stated behavioural intentions overestimate actual pro-environmental behaviour (Yüksel, 2017). Finally, scholars suggest that in contrast to the household setting, tourists face specific barriers (i.e., facility availability, "having a break") that might inhibit their willingness to behave in a more sustainable way (Dolnicar \& Grün, 2009; Miller et al., 2015).

\section{How to frame messages to trigger tourists' pro-environmental behaviours}

As previously discussed, tourists behave pro-environment either for self-interests or self-concept individuals' motives (i.e., self-benefit or moral appeals; Hardeman, Font \& Nawijn, 2017; Lee \& Oh, 2014).

In tourism, both of these approaches have been used as the basis of persuasive communication (Dolnicar et al., 2017; Goldstein et al., 2008; Hardeman et al., 2017; Schultz et al., 2008). However, the empirical effectiveness of the two approaches is still unclear. On the one hand, Goldstein et al. (2008) and Schultz et al. (2008) show that moral appeals led to an increasing in guests' sustainable behaviours (i.e., towel reuse). On the other hand, Hardeman et al. (2017) reveal that consumers exhibit more positive sustainable intentions in response to self-benefit appeals. In the same vein, Dolnicar et al. (2017) conclude that to elicit tourists' environmentally sustainable behaviour one possibility is to offer some kind of benefit and, in so doing, trigger the self-interest motive. 
Villarino and Font (2015) conclude that "the potential for tourism businesses to improve the persuasiveness of their sustainability communications is still largely unexplored" (p.333). It follows that an improvement to existing models and new theoretical angles are needed (Gao, Mattila \& Lee, 2016). Coherently, recent studies have proposed other message framing strategies (i.e., gain/loss framing; prevention/promotion framing; psychological distance) in the tourism setting (Blose, Mack \& Pitts, 2015; Lee \& Oh, 2014). However, the empirical validation of these theories is still in its infancy. The hedonic nature of tourism experiences in particular could reduce tourists' engagement towards pro-environmental behaviours (Dolnicar \& Grün, 2009). It has been argued that the tourism is about pleasure and not acting responsibly (Dolnicar et al. 2017). It follows that tourists reduce their proenvironmental behaviours because the vacation time is supposed to be worry-free, selfish time, and free of responsibilities (Dolnicar \& Grün, 2009; Miller et al. 2015). Based on this, we portray that showing tourists' possible negative consequences of their actions in a hedonic context could exert a change in their behaviours. Accordingly, to understand how persuasive messages can trigger tourists' pro-environmental behaviours, the present paper embraces Prospect Theory, Construal Level Theory and perceived self-efficacy as useful frameworks.

Table 1 summarizes the main contributions on these three theoretical frameworks.

Please insert Table 1 here

\section{Prospect Theory}

Tversky and Kahneman (1981) first illustrated Prospect Theory, which describes how people make decisions between alternatives that involve risk. According to this theory, the outcomes of the decisions can be framed as either perceived losses (loss frame) or 
perceived gains (gain frame). Specifically, a loss-framed message would highlight the disadvantages associated not to adopt the target action while a gain-framed message will emphasize the benefits of the target action (Meyers-Levy \& Maheswaran, 2004). For instance, a message that states "if you do not recycle, the environment will deteriorate" can be considered a loss-framed message. On the contrary, a message like "if you recycle, you conserve natural resources" can be considered a gain one. (Cheng, Woon, \& Lynes, 2011, p.52).

Prior research suggests that because of a more sensitivity towards loss aversion, negatively framed messages tend to be more effective than positively framed ones (Cheng et al., 2011; Kahneman \& Tversky, 1979; Meyerowitz \& Chaiken, 1987). It has been argued that individuals tend to dislike losses more than equivalent gains because of the well-documented negativity bias in our attention where "negative information exerts a greater impact on judgment than does objectively equivalent positive information" (Meyerowitz \& Chaiken, 1987, p.501).

Even though considerable research has addressed the question of the relative persuasiveness of loss- versus gain-framed message (O'Keefe \& Jensen, 2008; Salovey, Schneider, \& Apanovitch, 2002), the overall picture is still unclear. O'Keefe and Jensen (2007) conducted a meta-analysis of 93 studies and found a slightly significant advantage for gain-framed over loss-framed messages. Others found some evidence suggesting an overall stronger effectiveness of loss frames (e.g., Meyerowitz \& Chaiken, 1987; Tversky \& Kahneman, 1981). More specifically, these results are context-dependent and this tension is exemplified in the following tourism studies. On one hand, Kim and Kim (2014) showed that positive messages (gain-framed) are better able to affect guests' pro-environmental behaviours (i.e., visit intentions and water and energy saving). On the other hand, Blose et al. (2015) showed that, compared to gain 
framed messages, loss framed messages influence hotel guests' decision to engage in linen-reuse programs. In sum, it remains unclear whether (or when) loss frames are more effective than gain frames in encouraging consumer sustainable behaviours.

\section{Construal Level Theory}

Construal level theory (CLT) explains how psychological distance influences mental representation, judgment, and choice (Liberman \& Trope, 1998; Trope \& Liberman, 2003; Trope \& Liberman, 2010). According to CLT, objects, events, and individuals can be perceived as being psychologically near or distant, suggesting that the more psychologically distant an object is from the receiver of the message, the more abstract is the construal (Line, Hanks, \& Zhang, 2016). Psychological distance can vary in terms of time, space, social distance, probability, or any dimension that removes consumers from focusing on themselves in the here and now.

CLT postulates that any action can be viewed at varying levels of abstraction. At low construal level (concrete), individuals will focus on peripheral and detailed aspects (Aggarawal \& Zhao, 2015). Actions with a low level of construal would, therefore, specify "how" people do things, indicating the process associated with conducting a specific measurable action (e.g., I will reuse towels by hanging towels on the rack; Lee \& Oh, 2014; Zhu, He, Cheng, \& Hu, 2017). Conversely, at high construal level (abstract), people tend to process information more abstractly, looking at the big picture (Aggarwal \& Zhao, 2015). High level of construal deals with "why” people do things, explaining the reasons of such actions (e.g., I will reuse towels to help conserve the environment; Lee \& Oh, 2014; Zhu et al., 2017).

Recent research in the tourism and hospitality field stresses that CLT can be a useful framework to investigate the sustainability communication process and its 
persuasiveness (Lee \& Oh, 2014; Line et al., 2016; Teng \& Chang, 2014). For instance, Line et al. (2016) demonstrate how temporal, social and spatial distance influences consumer-level interpretations of an organization's sustainability message. In the same vein, Teng and Chang (2014) showed that temporal distance (future vs. near) has an effect in promoting hotel eco-friendly programs. Along these lines, Lee and Oh (2014) proposed that CLT can be applied to develop effective communication messages in the domain of sustainability.

\section{Perceived self-efficacy}

Perceived self-efficacy is concerned with people's beliefs in their capabilities to produce given attainments (Bandura, 1997). According to social cognitive theory (Bandura, 1986), behaviour greatly depends on perceived self-efficacy, which refers to “beliefs in one's capabilities to mobilize the motivation, cognitive resources, and courses of action needed to meet given situational demands" (Bandura, 1998, p. 624). Bandura (1997) further states that perceived self-efficacy beliefs influence not only perceptions of response efficacy but also emotional reactions, goals and aspirations, and perceptions of barriers and opportunities. Therefore, perceived self-efficacy beliefs influence behaviour or behavioural intention outcomes both directly and indirectly (Krieger \& Sarge, 2013).

In the tourism literature, self-efficacy beliefs have been found to positively affect pro-environmental behaviours (Shahzalal \& Font, 2018). For instance, selfefficacy predict intention to pay for environmental protection when travelling (Doran, Hanss \& Larsen, 2015), to engage with local community festivals (Jepson, Clarke \& Ragsdell, 2014), and to choose eco-friendly methods of travel (Doran, Hanss \& Øgaard, 2017).

Self-efficacy has been suggested as one of the most relevant mediators of loss- 
gain framing, among the others (i.e. regulatory focus, mood, level of involvement; Block \& Keller, 1995; Bosone \& Martinez, 2017; Meyers-Levy \& Maheswaran, 2004; Morton, Rabinovich, Marshall, \& Bretschneider, 2011; Rothman, Salovey, Antone, Keough \& Martin, 1993). It has been argued, indeed, that success in coping with highrisk situations depends partly on people's beliefs that they operate as active agents of their own actions and that they possess the necessary skills to obtain certain outcomes (Schwarzer \& Fuchs, 1995). Within this research stream, scholars suggest that perceived self-efficacy mediates the persuasiveness of the message (loss-framed/gainframed). However, results are mixed (Block \& Keller, 1995; Bosone \& Martinez, 2017; Meyers-Levy \& Maheswaran, 2004; Rothman et al., 1993). On the one hand, evidence suggests that loss framed messages, compared to gain framed, increase the ability to cope with risky situations (i.e., breast self-examination or MMR vaccine; Abhyankar et al.,2008; Meyerowitz \& Chaiken, 1987) and that this effect was mediated by increased feelings of self-efficacy. On the other hand, in the case of environmental behaviours some evidence supports a link between perceived gain-framed message and perceived self-efficacy (i.e., intentions to engage in environmental behaviour; Cheng et al., 2011; Morton et al., 2011).

\section{Conceptual Framework and Hypotheses Development}

Based on the literature above, our conceptual framework aims at testing the effect of loss-gain framed messages in triggering guests' pro-environmental behaviours (i.e., recycling behaviours), looking at the moderating effect of CLT and the mediation role of perceived self-efficacy.

Tourism literature suggests that both loss and gain frames can be effective under certain conditions, even though the valence of the message framing can differ (Blose et 
al. 2015; Lee \& Oh, 2014; Kim \& Kim 2014). In this regard, compared to not proving any message, the nudging literature (i.e., providing accessible information; Thaler \& Sunstein, 2008) suggests that creating any source of awareness is a valuable tool for increasing pro-environmental choices (Ölander \& Thøgersen, 2014). Given this, we portray that both loss and gain-framed messages can generate some persuasive effect in consumer recycling behaviour in hotels compared to the absence of any message.

Hence, we hypothesize that:

H1. With respect to no messages, the use of message framing, either loss-framed or gain-framed, will positively influence guests' recycling behaviours.

Moreover, emerging evidence suggests CLT as a possible moderator in loss-gain framing, arguing that its effect can be strengthened or weakened according to the level of construal (Lee \& Oh, 2014; White, MacDonnell, \& Dahl, 2011). Specifically, related to recycling behaviours, it has been argued that the effect of a loss-framed message will be intensified if the message stimulates information processing at a more concrete construal level, specifying how recycling is carried out (e.g., recycling by saving paper and aluminium cans). In the same vein, a gain-framed messages will be more effective when paired with a more abstract, higher level of construal, that focuses on generic reasons behind recycling (e.g., recycling to help environmental sustainability) (Lee \& Oh, 2014; White et al., 2011). Based on this, it is expected that the effectiveness of a persuasive communication message will be enhanced when the valence of the loss-gain frame is aligned with appropriate construal level of the message. Therefore, it is hypothesized that:

H2. The construal level of the message moderates the impact of loss-gain framing on hotel guests' recycling behaviour: 
- H2a: Compared with a low-level construal (concrete) paired with a gain frame, guests' recycling behaviours are enhanced when a low-level construal (concrete) is paired with a loss green message framing.

- H2b: Compared with a high-level construal (abstract) paired with a loss frame, guests' recycling behaviours are enhanced when a high-level construal (abstract) is paired with a gain green message framing.

Finally, the use of loss-gain framing will positively influence consumers' behaviours through perceived self-efficacy activation. However, to reconcile different findings in the literature we suggest that this mechanism appears when the loss-gain framing is matched with the construal level of the message (concrete/abstract). Hence, we propose that a match in messaging leads to a greater perceived self-efficacy, resulting consequently in more positive recycling intentions and behaviours.

H3: The impact of the interaction between loss-gain framing and construal levels on recycling intentions is mediated by perceived self-efficacy (interaction $\rightarrow$ perceived self-efficacy $\rightarrow$ recycling intentions).

Figure one presents graphically the proposed model. Hypothesis 1 (H1) indicates that loss/gain framed messages will have a main positive effect on recycling behaviours of hotel guests. Hypothesis 2 (H2) suggests that the level of the message, whether concrete (low-level of construal) or abstract (high-level of construal), moderates this main effect. Hypothesis 3 (H3) proposes that this interaction effect on recycling intentions is mediated by perceived self-efficacy.

Please Insert Figure 1 near here 


\section{Methodology}

Methodologically, the article presents two experimental studies. Study 1 is a field study that measures the actual recycling behaviour of hotel guests and goes beyond stated intentions that may suffer from self-response biases (Dolnicar et al., 2017). Study 2 is a laboratory study that investigates the psychological mechanism (i.e., perceived selfefficacy) behind the relation between loss-gain framing and recycling intentions (Lynch, 1999).

The rationale for adopting both a field and a laboratory study lies so that there is both external and internal validity in the results (Gneezy, 2017; Lynch, 1999). Scholars suggest to start with a field experiment and, if necessary, follow up with laboratory experiments to understand the process's underpinning the effect (Fong, Fang \& Luo 2015; Gneezy, 2017). Specifically, a field experiment's main advantage is its high external validity, because it measures real human behaviours (Goldstein et al., 2008; Gneezy, 2017; Mair \& Bergin-Seers, 2010). However, field experiments have the disadvantage of being extremely labour intensive, highly time consuming and prone to bias by unexpected events that are not under the control of the researchers, especially for what concerns a tourist setting (i.e., hotels, restaurants and alike) (Cvelbar et al., 2017; Dolnicar et al., 2017; Gneezy, 2017). The main advantage of the lab study is, instead, testing for the mechanism behind the proposed relationship, thus proving the internality validity (Lynch, 1999).

\section{Study 1}

In Study 1 we test the persuasive effect of loss and gain framed message on consumer hotel recycling behaviour (H1) and the moderating role of the level of construal (concrete vs. abstract) (H2). More specifically, coherently with the theoretical 
underpinning above, we investigate whether loss frames are particularly effective when paired with low-level, concrete information whereas gain frames are particularly effective when paired with high-level, abstract information.

The study was run in a midscale hotel in the UK in June 2017. We assigned all the rooms of the 5-floor hotel to one of five different conditions (four manipulated conditions and a control condition). Specifically, 360 rooms were randomized across the four conditions (i.e., loss-concrete; loss-abstract; gain-concrete; gain-abstract) while 74 were in the control condition (no-message). We randomized our treatments and control across the floors and the rooms in each floor, to avoid a systematic effect on the type of room on the condition. For a period of five days, the management let us systematically measure the recycling behaviour of guests. Regarding the design and procedure adopted, we prepared a two-sided door hanger (flyer) for each room. One side of the hanger presented the frame manipulation, either a loss-framed or a gain-framed message. Specifically, the message in the loss condition was designed to highlight the negative consequences by not recycling (i.e., "Think about what we will lose if we don't recycle"... "By not recycling, we waste over 12.5 million tonnes of paper and cardboard"). On the contrary, the gain condition presented the positive consequences achievable by recycling ("Think about what we will gain if we recycle... "By recycling, we save over 12.5 million tonnes of paper and cardboard"). The other side presented the construal level, either concrete (i.e., how to recycle - "Throw your waste into the specific bin (paper, plastic and/or glass)") or abstract (i.e., why to recycle - "Recycling save the quality of our air, land and water resources") (figure 2a, 2b, 2c and 2d). Each room presented 3 small bins, a general waste bin and two recycle bins, for plastic and paper, respectively. Two trained cleaning people were blind to the hypotheses and conditions and took ratings of recycling behaviour during the five days. They were 
provided with detailed instructions in advance of completing their ratings. When they disagreed on a score, they discussed their differences and came to an agreement.

Please Insert Figures 2a, 2b, 2c, 2d near here

Our dependent variable was guests' recycling rates, which corresponded to the amount of waste placed in the appropriate recycling bins. Specifically, we measured the proportion of recycled material with respect to the total possible recyclable material by looking at the ratio between the material correctly inserted in the recycled bins over the total potential recyclable waste inserted in all the bins in the room. The index was in a 0-0.25-0.5-0.75-1 index, where 0 corresponded to completely absence of recycling behaviour, 1 corresponded to maximum possible recycling behaviour and intermediate values to situations where there was a partial recycling behaviour.

\section{Study 2}

Study 2 is based on a laboratory study and has been designed to disclose the mechanism driving the effect of loss-gain framing on recycling intentions. Lab experiments allow for explanations under controlled conditions and an exploration of the mechanism behind the proposed relation, thus providing internal validity (Calder et al., 1981). Although based on convenience samples, lab studies are commonly adopted for theory testing (Šerić \& Praničević, 2018).

Study 2 proposes that a match between a loss frame with a more concrete level of construal will lead to enhanced perceived self-efficacy (i.e., the belief of being capable of performing in a certain manner to attain a particular goal; Bandura, 1997), which consequently affects recycling intentions (H3).

The study was run in UK in September 2017. A sample of 145 respondents took part in the study. The sampling process was stratified in that we selected participants 
who were familiar with the hotel context (i.e., have booked and stayed at a hotel at least one time). A 2 (message frame: loss vs. gain) x 2 (appeal type: how vs. why) betweensubjects experimental design has been adopted. In this study, participants viewed one of the loss/how, loss/why, gain/how, or gain/why versions of the materials used in Study 1 (see Figure 2a, 2b, 2c and 2d). After that, participants were asked to complete measures of perceived self-efficacy and intentions to recycle. We included two manipulations checks on loss and gain framing to see if the manipulations were perceived as meant.

The key variables of interest (i.e., recycling intentions and perceived selfefficacy) have been measured using previous validated scales. Participants provided ratings of perceived self-efficacy $(\alpha=.97)$ by using a 3 -item measure developed by White et al. (2011): "I feel that by recycling I can make a difference", "I feel that I know how to go about recycling", "I believe that I know what steps I will take to recycle". Participants indicated the degree of their agreement with these items by using a 7-point Likert scale $(1=$ strongly disagree; $7=$ strongly agree $)$. They also provided ratings of recycling intentions ( $\alpha=.94$ ) by using a 3-item measure adapted from Lee and Aaker (2004): "How likely are you to use this hotel recycling program?", "How inclined are you to use this hotel recycling program?", "How willing are you to use this hotel recycling program?". Participants indicated the degree of their agreement with these items by using a 7-point Likert scale. Finally, we included gender and age as controls in the model.

\section{Results}

\section{Study 1}

A pilot test was conducted in order to test for the used manipulations. Twenty-eight participants took part to the study $\left(\mathrm{M}_{\mathrm{age}}=26 ; 64 \%\right.$ female $)$. Participants were randomly 
assigned to one of four treatment conditions (loss-concrete; loss-abstract; gain-concrete; gain-abstract; see Figure 2a, 2b, 2c and 2d). Then they were asked to rate to what extent the message shown was a loss or gain framed message as well as a concrete (how to recycle) or an abstract (why to recycle) message. Results reveal the intended effect of our manipulations for the loss-framed message and for the concrete construal level of the message. Participants in the loss condition expressed significantly greater degree in stating that the advertising was focused on losses $\left(\mathrm{M}_{\text {loss }}=5.17, \mathrm{M}_{\text {gain }}=2.31, \mathrm{p}<0.01\right)$. In the same vein, participants in the concrete condition (how) expressed significantly greater degree in stating that the advertising was focused on ways to make a difference (to recycle) than those in the abstract condition (why) $\left(\mathrm{M}_{\text {concrete }}=5.23, \mathrm{M}_{\text {abstract }}=2.60, \mathrm{p}<\right.$ $0.01)$.

Table 2 presents the main descriptive statistics from the field experiment. Table 3 complements Table 2 by showing some statistics for the variables related to the recycling behaviour divided in to four conditions (loss-abstract, loss-concrete, gainabstract and gain-concrete).

Insert Table 2 about here

Insert Table 3 about here

As Table 2 shows, approximately the same proportion of guests were assigned to the loss $(50 \%)$ and gain (50\%) conditions. Slightly less than half of the customers were business travellers $(47 \%)$ while $54 \%$ of customers were female.

First, we checked if any framing was more effective than no framing at all (no flyers). Overall, our results show that in the no-message condition recycling rates are around $30 \%$, while in the loss-gain condition are significantly higher (respectively $50 \%$ and 39\%). These results allow us to conclude that overall, showing a message (either loss or gain framed) is better that no message at all, supporting our H1. In addition, 
recycling guests' behaviours are significantly greater in the loss $(50 \% ; \mathrm{p}<0.05)$ and barely significant in the gain $(39 \% ; p<0.10)$ framing condition with respect to the control condition (no message).

Table 3 indicates that recycling behaviour was not different between the lossabstract versus gain-abstract $(p>0.05)$. However, there was a significant difference in recycling behaviour between loss/concrete vs gain/concrete conditions $(p<0.01)$, showing an average increase in approximately $22 \%$ in loss/concrete condition.

Table 4 presents the results of an OLS regression analysis, with recycling behaviour as the dependent variable. The explanatory variables in the full regression model include all the variables in Table 2, as there were no issues of multicollinearity by means of variance inflation factor (VIF below 2.5 for all the pairwise correlations). To test for the moderation effects between message framing and construal level, the interaction between loss and concrete (LossXConcrete) are included in the model.

\section{Insert Table 4 about here}

The regression, which controls for single/multiple night stays by clustering multiple observations from the same individual, suggests that the presence of a loss-gain or a concrete-abstract framed message does not have a significant influence on recycling behaviour. However, a message framed with loss matched with a more concrete level of the message produces more positive recycling behaviours among consumers. In sum, $\mathrm{H} 2 \mathrm{a}$ is supported but $\mathrm{H} 2 \mathrm{~b}$ does not find evidence in the data. Introducing control variables in the regression analysis helps to further explore potential determinants of recycling behaviour. Only gender proved to be significant, with females demonstrating higher level of recycling behaviour. 


\section{Study 2}

One hundred and forty-five participants took part in Study 2. The sample comprised $59 \%$ female, while the average age was 25.8 years $($ s.d. $=5.73)$. We first checked for the manipulations. In this regard, results showed that participants in the loss condition expressed significantly greater degree in stating that the advertising was focused on losses $\left(\mathrm{M}_{\text {loss }}=4.45, \mathrm{M}_{\text {gain }}=3.32, \mathrm{p}<0.01\right)$. In the same vein, participants in the concrete condition (how) expressed significantly greater degree in stating that the advertising was focused on ways to make a difference (to recycle) than those in the abstract condition (why) $\left(\mathrm{M}_{\text {concrete }}=4.49, \mathrm{M}_{\mathrm{abstract}}=3.43, \mathrm{p}<0.01\right)$.

Study 2 tested for mediating role of perceived self-efficacy. According to H3, we predicted that the impact of the interaction between message framing and construal levels on recycling intentions is mediated by perceived self-efficacy. We tested a moderated mediation model using the PROCESS macro (Model 7) by Hayes (2013), with loss-gain framing message as the independent variable, the construal level of the message as the moderator of the effect of message framing on recycling intentions, and perceived self-efficacy as the mediator. As established in prior experimental research, we used a dummy variable coding approach to include experimental treatments as the independent variables in the model (Bagozzi, 1977). That is, we coded one dummy variable for message framing ( 0 gain-framed message vs. 1 loss-framed message) and another dummy variable for construal level of the message ( 0 abstract vs. 1 concrete).

Providing support for this moderated mediation process model, the loss-framed message $\mathrm{x}$ concrete level of construal interaction had a significant effect on perceived self-efficacy (mediator) $(\beta=2.80, \mathrm{SE}=0.30, \mathrm{t}(139)=9.09, p<.001)$. In turn, perceived self-efficacy had a significant and positive effect on recycling intentions $(\beta=$ $.30, \mathrm{SE}=0.11, \mathrm{t}(138)=2.70, p<.01)$. The interaction of loss-framed message $\mathrm{x}$ 
concrete level of construal was no longer a significant predictor of recycling intentions after controlling for the mediator, perceived self-efficacy $(\beta=.71, \mathrm{SE}=0.52, \mathrm{t}(138)=$ $1.35, p=.176$ ), which indicates that self-efficacy fully mediates the interaction. The model includes gender and age as controls (Table 5). The significance of the indirect effect of perceived self-efficacy was verified across each level of the construal of the message with bootstrapped standard errors and 95\% confidence intervals (CIs).

Moreover, the indirect effect of perceived self-efficacy was significant at the concrete level but not at the abstract level of the construal message, as graphically reported in the plot (Figure 3). Specifically the lower part of Table 5 presents the indirect effect of perceived self-efficacy on recycling intentions via construal level of the message. For abstract level of construal, results are not significant (because the limit of the $95 \% \mathrm{CI}$ includes zero). However, for concrete level of construal, results reveal a significant positive indirect effect $(\beta=0.9068,95 \%$ confidence interval $[\mathrm{CI}]=[.2907,1.4945])$.

Please Insert Table 5 near here

Please Insert Figure 3 near here

\section{Discussion}

Across a field and a lab experiment, this research uncloses the conditions under which hotel guests are more (or less) likely to report positive intentions toward recycling and actually engage in recycling behaviour. Overall, results indicate that a message framed as a negative loss (rather than a positive gain) matched with a more concrete level of the message produces more positive consumer recycling intentions and behaviours, explained by a greater perceived self-efficacy.

In particular, the findings from our field study suggest that both loss or gain messages have a positive effect in overall recycling behaviours with respect to the 
absence messages. This is in line with the nudging literature (Thaler \& Sunstein, 2008) which suggests that creating any source of awareness is a valuable tool for increasing pro-environmental choices (Ölander \& Thøgersen, 2014). Moreover, our findings suggest that a loss-framed message generates higher rates of guests' recycling behaviours (approximately 50\%) than gain (39\%) and no message condition (30\%). This is similar to the results of Blose et al. (2015) who show that, compared to gain framed messages, loss framed ones influence hotel guests' decision to engage in linenreuse programs. This suggests that, without a clear loss frame, tourists might like the idea of environmentally sustainable tourism, but they do not like it enough to actually adjust their behaviour to be more environmentally friendly (e.g. Dolnicar \& Grün, 2009; Juvan \& Dolnicar, 2014; Karlsson \& Dolnicar, 2016; Miller, Rathouse, Scarles, Holmes $\&$ Tribe, 2010). Our results support that negatively framed messages tend to be more effective than positive ones.

Study 1 also tests for the moderating role of CLT. It has been argued that a lossgain effect can be strengthened or weakened according to the level of construal (Lee \& Oh, 2014; White et al., 2011). In this regard, the results show that a message framed as a loss paired with a more concrete level of construal leads to an increase of around $22 \%$ on actual recycling behaviour (see Table 3). This is consistent with the study by White et al. (2011, study 1) who found that a message framed as a loss paired with a more concrete level of construal is highly effective in fostering recycling behaviours. It follows that people seem to be more engaged in adopting recycling actions when they can exactly understand how to do it rather than thinking about generic reasons behind recycling. However, our results do not support that an abstract construal matched with a gain frame is effective in engaging guests' recycling behaviours and intentions (Morton et al., 2011). 
Study 2 investigates the psychological mechanism driving this effect under more controlled conditions (Lynch, 1999). Extant literature suggests that self-efficacy beliefs (Bandura, 1998) positively affect pro-environmental behaviours (Shahzalal \& Font, 2018). According to this, we propose that a match in messaging leads to a greater perceived self-efficacy, resulting consequently in more positive recycling intentions. Results of Study 2 provide support for this hypothesis, supporting that a match between a loss frame with a more concrete level of construal leads to enhanced perceived selfefficacy, which, in turn, affects recycling intentions.

\section{Conclusion, implications and further research}

The tourism literature seeks to understand the relationship between tourism and environmental friendly behaviours. In this regard, a key priority is engaging tourists to be active partners in reducing their environmental impact (Warren et al., 2016). This interdisciplinary work integrates new theoretical insights from social science (i.e., Prospect Theory and CLT) and some experimental evidence on the role of persuasive messages on recycling behaviour. More specifically, this study proposes that a loss or gain-framed message influences pro-environmental behaviour of hotel guests, suggesting that the construal level of the message (concrete vs. abstract) might moderate this relationship and reconcile previous contrasting findings (Lee \& Oh, 2014; White et al., 2011). In addition, we sought to investigate the theoretical mechanism underlying this effect by arguing that perceived self-efficacy act as a mediator of this relationship.

Theoretically, the present study contributes to the existing knowledge on environmentally sustainable tourist behaviour in at least three ways. First, it extends the body of research on framing strategies that might induce more pro-environmental behaviours in the tourism context. Specifically, drawing from Prospect Theory and CLT, which have been rarely used in tourism, this study provides evidence of their 
effectiveness in hotel green messages. Second, this is the first study in the tourism field that empirically tests the matching between loss-gain framing and the construal level of the message through an experimental design, thus proving a new theoretical framework to investigate pro-environmental behaviours. Another key theoretical contribution of this research lies in answering the call posed by Dolnicar and Ring (2014). The present study, indeed, measures actual behaviours and investigates recycling in hotels, which has been scarcely studied (Juvan \& Dolnicar, 2016).

This research presents clear managerial implications for hoteliers that aim to engage their guests to be active partners in pro-environmental behaviours. As sustainability becomes an ever more important part of tourism companies' strategies (Warren et al., 2016), an effective communication of green initiatives to consumers is of paramount importance to reduce costs and preserving natural resources. Fostering guests' recycling behaviours in hotel would mean saving thousands pounds of waste management cost every year. Specifically, hotels should design green messages to their guests highlighting the negative consequences of not adopting sustainable behaviours (such as recycling), and giving them instructions on how to avoid such consequences rather than explaining reasons to avoid them. In this way, hoteliers can reinforce hotel guests' believes to be capable of acting in a more pro-environmental manner.

The present study is not without limitations. First, the field study was conducted in one hotel of a specific country. Therefore, replication studies in other tourism domains (i.e., travel industry) are necessary to ensure generalizability of the findings. In addition, further research can address the increasing concerns on how reducing tourism environmental impact (e.g., food waste in airlines) and propose valuable strategies and solutions (i.e., reduce environmental impact, saving costs and alike) to tourism managers. Second, although at the check-in customers were informed of the presence of 
a door hangar and at the check-out they were asked to state if they had read the door hangar flyer (and they all responded positively), we do not have a proper post-test due to a hotel request to avoid giving clients a quick final survey. Third, the lab study, used for testing the mechanism behind the proposed relation, is based on a convenience sample (i.e., students with previous experience in hotel bookings). Finally, the study only measures recycling behaviour through the proportional amount of the included waste in the recycling bins. Future work should extend the investigation to other behaviours, such as water use, energy conservation and towel reuse. We leave this for future research.

\section{References}

Abhyankar, P., O'connor, D. B., \& Lawton, R. (2008). The role of message framing in promoting MMR vaccination: Evidence of a loss-frame advantage. Psychology, Health and Medicine, 13(1), 1-16.

Abrahamse, W., \& Steg, L. (2009). How do socio-demographic and psychological factors relate to households' direct and indirect energy use and savings? Journal of Economic Psychology, 30(5), 711-720.

Aggarwal, P., \& Zhao, M. (2015). Seeing the Big Picture: The Effect of Height on the Level of Construal. Journal of Marketing Research, 52(1), 120-133.

Ajzen, I. (1991). The theory of planned behavior. Organizational Behavior and Human Decision Processes, 50(2), 179-211.

Bagozzi, R. P. (1977). Structural equation models in experimental research. Journal of Marketing Research, 14(2), 209-226.

Bamberg, S., \& Möser, G. (2007). Twenty years after Hines, Hungerford, and Tomera: A new meta-analysis of psycho-social determinants of pro-environmental behavior. Journal of Environmental Psychology, 27(1), 14-25.

Bandura, A. (1986). Social foundations of thought and action: A social cognitive theory. Englewood Cliffs, NJ: Prentice-Hall.

Bandura, A. (1997). Self-efficacy: The exercise of control. New York: Freeman. 
Bandura, A. (1998). Health promotion from the perspective of social cognitive theory. Psychology and health, 13(4), 623-649.

Blake, J. (1999). Overcoming the 'value-action gap'in environmental policy: Tensions between national policy and local experience. Local environment, 4(3), 257-278.

Block, L. G., \& Keller, P. A. (1995). When to accentuate the negative: The effects of perceived efficacy and message framing on intentions to perform a healthrelated behavior. Journal of Marketing Research, 32(2)192-203.

Blose, J. E., Mack, R. W., \& Pitts, R. E. (2015). The influence of message framing on hotel guests' linen-reuse intentions. Cornell Hospitality Quarterly, 56(2), 145154.

Bolderdijk, J. W., Gorsira, M., Keizer, K., \& Steg, L. (2013). Values determine the (in) effectiveness of informational interventions in promoting pro-environmental behavior. PLoS One, 8(12), e83911.

Bosone, L., \& Martinez, F. (2017). When, How and Why is Loss-Framing More Effective than Gain-and Non-Gain-Framing in the Promotion of Detection Behaviors?. International Review of Social Psychology, 30(1), 184-192.

Brown, T. J., Ham, S. H., \& Hughes, M. (2010). Picking up litter: An application of theory-based communication to influence tourist behaviour in protected areas. Journal of Sustainable Tourism, 18(7), 879-900.

Buckley, R. (2012). Sustainable tourism: Research and reality. Annals of Tourism Research, 39(2), 528-546.

Calder, B. J., Phillips, L. W., \& Tybout, A. M. (1981). Designing research for application. Journal of Consumer Research, 8(2), 197-207.

Chan, W. W., \& Lam, J. C. (2003). Energy-saving Supporting Tourism Sustainability: A Case Study of Hotel Swimming Pool Heat Pump. Journal of Sustainable Tourism, 11(1), 74-83.

Chen, A., \& Peng, N. S. (2012). Green hotel knowledge and tourists' staying behavior. Annals of Tourism Research, 39(4), 2211-2216.

Chen, M. F., \& Tung, P. J. (2014). Developing an extended theory of planned behavior model to predict consumers' intention to visit green hotels. International Journal of Hospitality Management, 36, 221-230. 
Cheng, T., Woon, D. K., \& Lynes, J. K. (2011). The use of message framing in the promotion of environmentally sustainable behaviors. Social Marketing Quarterly, 17(2), 48-62.

Cvelbar, L. K., Grün, B., \& Dolnicar, S. (2017). Which hotel guest segments reuse towels? Selling sustainable tourism services through target marketing. Journal of Sustainable Tourism, 25(7), 921-934.

Dickinson, J. E., Lumsdon, L. M., \& Robbins, D. (2011). Slow travel: issues for tourism and climate change. Journal of Sustainable Tourism, 19(3), 281-300.

Dolnicar, S., \& Grün, B. (2009). Environmentally friendly behavior: Can heterogeneity among individuals and contexts/environments be harvested for improved sustainable management?. Environment and Behavior, 41(5), 693-714.

Dolnicar, S., \& Ring, A. (2014). Tourism marketing research: Past, present and future. Annals of Tourism Research, 47, 31-47.

Dolnicar, S., Cvelbar, L.K., \& Grün, B. (2017). Do Pro-environmental Appeals Trigger Pro-environmental Behavior in Hotel Guests? Journal of Travel Research, 56(8), 988-997.

Doran, R., Hanss, D., \& Larsen, S. (2015). Attitudes, efficacy beliefs, and willingness to pay for environmental protection when travelling. Tourism and Hospitality Research, 15(4), 281-292.

Doran, R., Hanss, D., \& Øgaard, T. (2017). Can Social Comparison Feedback Affect Indicators of Eco-Friendly Travel Choices? Insights from Two Online Experiments. Sustainability, 9(2), 196-211.

Dunning, D. (2007). Self-Image Motives and Consumer Behavior: How Sacrosanct Self-Beliefs Sway Preferences in the Marketplace. Journal of Consumer Psychology, 17(4), 237-249.

Dwyer, L., Forsyth, P., Spurr, R., \& Hoque, S. (2010). Estimating the carbon footprint of Australian tourism. Journal of Sustainable Tourism, 18(3), 355-376.

Egea, J. M. O., \& Frutos, N. G. (2013). Toward Consumption Reduction: An Environmentally Motivated Perspective. Psychology \& Marketing, 30(8), 660675.

Esparon, M., Gyuris, E., Stoeckl, N. (2013). Does ECO certification deliver benefits? An empirical investigation of visitors' perceptions of the importance of ECO 
certification's attributes and of operators' performance. Journal of Sustainable Tourism, 22(1), 148-169.

Fishbein, M., \& Ajzen, I. (1975). Belief, attitude, intention, and behavior: an introduction to theory and research: Addison-Wesley Pub. Co.

Fong, N. M., Fang, Z., \& Luo, X. (2015). Geo-conquesting: Competitive locational targeting of mobile promotions. Journal of Marketing Research, 52(5), 726-735.

Font, X., \& McCabe, S. (2017). Sustainability and marketing in tourism: its contexts, paradoxes, approaches, challenges and potential. Journal of Sustainable Tourism, 25(7), 869-883.

Gao, Y. L., Mattila, A. S., \& Lee, S. (2016). A meta-analysis of behavioral intentions for environment-friendly initiatives in hospitality research. International Journal of Hospitality Management, 54, 107-115.

Gneezy, A. (2017). Field experimentation in marketing research. Journal of Marketing Research, 54(1), 140-143.

Goldstein, N. J., Cialdini, R. B., \& Griskevicius, V. (2008). A room with a viewpoint: Using social norms to motivate environmental conservation in hotels.Journal of consumer Research, 35(3), 472-482.

Gössling, S., \& Peeters, P. (2015). Assessing tourism's global environmental impact 1900-2050. Journal of Sustainable Tourism, 23(5), 639-659.

Han, H., \& Yoon, H. J. (2015). Hotel customers' environmentally responsible behavioral intention: Impact of key constructs on decision in green consumerism. International Journal of Hospitality Management, 45, 22-33.

Han, H., Hsu, L.-T., \& Sheu, C. (2010). Application of the Theory of Planned Behavior to green hotel choice: Testing the effect of environmental friendly activities. Tourism Management, 31(3), 325-334

Hardeman, G., Font, X., \& Nawijn, J. (2017). The power of persuasive communication to influence sustainable holiday choices: Appealing to self-benefits and norms. Tourism Management, 59, 484-493.

Hayes, A. F. (2013). Introduction to mediation, moderation, and conditional process analysis: A regression-based approach. Guilford Press.

Hergesell, A., \& Dickinger, A. (2013). Environmentally friendly holiday transport mode choices among students: the role of price, time and convenience. Journal of Sustainable Tourism, 21(4), 596-613. 
Jepson, A., Clarke, A., \& Ragsdell, G. (2014). Investigating the Application of the Motivation-Opportunity-Ability Model to Reveal Factors Which Facilitate or Inhibit Inclusive Engagement Within Local Community Festivals. Scandinavian Journal of Hospitality and Tourism, 14(3), 331-348.

Juvan, E. \& Dolnicar, S. (2016) Measuring Environmentally Sustainable Tourist Behavior. Annals of Tourism Research, 59, 30-44.

Juvan, E., \& Dolnicar, S. (2014). The attitude-behavior gap in sustainable tourism. Annals of Tourism Research, 48, 76-95.

Kahneman, D., \& Tversky, A. (1979). Prospect Theory: An Analysis of Decision under Risk. Econometrica, 47(2), 263-291.

Karlsson, L., \& Dolnicar, S. (2016). Does eco certification sell tourism services? Evidence from a quasi-experimental observation study in Iceland. Journal of Sustainable Tourism, 24(5), 694-714.

Kiatkawsin, K., \& Han, H. (2017). Young travelers' intention to behave proenvironmentally: merging the value-belief-norm theory and the expectancy theory. Tourism Management, 59, 76-88.

Kim, S.-B., \& Kim, D.-Y. (2014). The effects of message framing and source credibility on green messages in hotels. Cornell Hospitality Quarterly, 55(1), 64-75.

Kim, Y. J., Njite, D., \& Hancer, M. (2013). Anticipated emotion in consumers' intentions to select eco-friendly restaurants: Augmenting the theory of planned behavior. International Journal of Hospitality Management, 34, 255-262.

Kim, Y., \& Han, H. (2010). Intention to pay conventional-hotel prices at a green hotel-a modification of the theory of planned behavior. Journal of Sustainable Tourism, 18(8), 997-1014.

Kormos, C., \& Gifford, R. (2014). The validity of self-report measures of proenvironmental behavior: A meta-analytic review. Journal of Environmental Psychology, 40, 359-371.

Krieger, J. L., \& Sarge, M. A. (2013). A serial mediation model of message framing on intentions to receive the human papillomavirus (HPV) vaccine: revisiting the role of threat and efficacy perceptions. Health communication, 28(1), 5-19.

Landon, A. C., Woosnam, K. M., \& Boley, B. B. (2018). Modeling the psychological antecedents to tourists' pro-sustainable behaviors: an application of the valuebelief-norm model. Journal of Sustainable Tourism, 1-16. 
Lee, S., \& Oh, H. (2014). Effective Communication Strategies for Hotel Guests' Green Behavior. Cornell Hospitality Quarterly, 55(1), 52-63.

Lee, T. H., Jan, F. H., \& Yang, C. C. (2013). Conceptualizing and measuring environmentally responsible behaviors from the perspective of communitybased tourists. Tourism Management, 36, 454-468.

Lee, A.Y., \& Aaker, J.L. (2004). Bringing the frame into focus: the influence of regulatory fit on processing fluency and persuasion. Journal of personality and social psychology, 86(2), 205.

Liberman, N., \& Trope, Y. (1998). The role of feasibility and desirability considerations in near and distant future decisions: A test of temporal construal theory. Journal of Personality and Social Psychology, 75(1), 5-18.

Liberman, N., \& Trope, Y. (2008). The psychology of transcending the here and now. Science, 322(5905), 1201-1205.

Lindenberg, S., \& Steg, L. (2007). Normative, Gain and Hedonic Goal Frames Guiding Environmental Behavior. Journal of Social Issues, 63(1), 117-137.

Line, N. D., Hanks, L., \& Zhang, L. (2016). Sustainability communication: The effect of message construals on consumers' attitudes towards green restaurants. International Journal of Hospitality Management, 57, 143-151.

Lynch, J. G. (1999). Theory and external validity. Journal of the Academy of Marketing Science, 27(3), 367-376.

Mair, J., \& Bergin-Seers, S. (2010). The effect of interventions on the environmental behaviour of Australian motel guests. Tourism and Hospitality Research, 10(4), 255-268.

Mazar, N., \& Zhong, C.-B. (2010). Do Green Products Make Us Better People? Psychological Science, 21(4), 494-498.

Mehmetoglu, M. (2010). Factors influencing the willingness to behave environmentally friendly at home and holiday settings. Scandinavian Journal of Hospitality and Tourism, 10(4), 430-447.

Meyerowitz, B. E., \& Chaiken, S. (1987). The effect of message framing on breast selfexamination attitudes, intentions, and behavior. Journal of Personality and Social Psychology, 52(3), 500-510. 
Meyers-Levy, J., \& Maheswaran, D. (2004). Exploring Message Framing Outcomes When Systematic, Heuristic, or Both Types of Processing Occur. Journal of Consumer Psychology (Lawrence Erlbaum Associates), 14(1/2), 159-167.

Miao, L., \& Wei, W. (2013). Consumers' pro-environmental behavior and the underlying motivations: A comparison between household and hotel settings. International Journal of Hospitality Management, 32, 102-112.

Miller, D., Merrilees, B., \& Coghlan, A. (2015). Sustainable urban tourism: Understanding and developing visitor pro-environmental behaviours. Journal of Sustainable Tourism, 23(1), 26-46.

Miller, G. (2003). Consumerism in sustainable tourism: A survey of UK consumers. Journal of Sustainable Tourism, 11(1), 17-39.

Miller, G., Rathouse, K., Scarles, C., Holmes, K., \& Tribe, J. (2010). Public understanding of sustainable tourism. Annals of tourism research, 37(3), 627645.

Morton, T. A., Rabinovich, A., Marshall, D., \& Bretschneider, P. (2011). The future that may (or may not) come: How framing changes responses to uncertainty in climate change communications. Global Environmental Change, 21(1), 103109.

Myung, E., McClaren, A., \& Li, L. (2012). Environmentally related research in scholarly hospitality journals: Current status and future opportunities. International Journal of Hospitality Management, 31(4), 1264-1275.

Oates, C. J., \& McDonald, S. (2014). The researcher role in the attitude-behaviour gap. Annals of Tourism Research, 46, 168-170.

O'Keefe, D. J., \& Jensen, J. D. (2007). The Relative Persuasiveness of Gain-Framed Loss-Framed Messages for Encouraging Disease Prevention Behaviors: A MetaAnalytic Review. Journal of Health Communication, 12(7), 623-644.

O'Keefe, D. J., \& Jensen, J. D. (2008). Do loss-framed persuasive messages engender greater message processing than do gain-framed messages? A meta-analytic review. Communication Studies, 59(1), 51-67.

Ölander, F., \& Thøgersen, J. (2014). Informing Versus Nudging in Environmental Policy. Journal of Consumer Policy, 37(3), 341-356. 
Prillwitz, J., \& Barr, S. (2011). Moving towards sustainability? Mobility styles, attitudes and individual travel behaviour. Journal of Transport Geography, 19(6), 15901600.

Radwan, H. R. I., Jones, E., \& Minoli, D. (2012). Solid waste management in small hotels: a comparison of green and non-green small hotels in Wales. Journal of Sustainable Tourism, 20(4), 533-550.

Rothman, A. J., Salovey, P., Antone, C., Keough, K., \& Martin, C. D. (1993). The influence of message framing on intentions to perform health behaviors. Journal of experimental social psychology, 29(5), 408-433.

Sachdeva, S., Iliev, R., \& Medin, D. L. (2009). Sinning saints and saintly sinners: the paradox of moral self-regulation. Psychol Sci, 20(4), 523-528.

Salovey, P., Schneider, T. R., \& Apanovitch, A. M. (2002). Message framing in the prevention and early detection of illness. In J. P. Dillard \& M. Pfau (Eds.), The persuasion handbook: Developments in theory and practice (pp. 391-406). Thousand Oaks, CA: Sage.

Schultz, W. P., Khazian, A. M., \& Zaleski, A. C. (2008). Using normative social influence to promote conservation among hotel guests. Social Influence, 3(1), 423.

Schwartz, S. H. (1977). Normative influences on altruism. Advances in experimental social psychology, 10, 221-279.

Schwartz, S. H., \& Howard, J. A. (1981). Altruism and helping behavior: social, personality, and developmental perspectives. Hillsdale, N.J.: Lawrence Erlbaum Associates.

Schwarzer, R., \& Fuchs, R. (1995). Changing risk behaviors and adopting health behaviors: The role of self-efficacy beliefs. Self-efficacy in changing societies, 259-288.

Šerić, M., \& Praničević, D. G. (2018). Consumer-generated reviews on social media and brand relationship outcomes in the fast-food chain industry. Journal of Hospitality Marketing \& Management, 27(2), 218-238.

Shahzalal, M., \& Font, X. (2018). Influencing altruistic tourist behaviour: Persuasive communication to affect attitudes and self-efficacy beliefs. International Journal of Tourism Research, 20(3), 326-334. 
Shanklin, C. W., Petrillose, M. J., \& Pettay, A. (1991). Solid Waste Management Practices in Selected Hotel Chains and Individual Properties. Hospitality Research Journal, 15(1), 59-74.

Stern, P. C. (2000). Toward a Coherent Theory of Environmentally Significant Behavior. Journal of Social Issues, 56(1), 407-424.

Styles, D., Schönberger, H., \& Martos, J. L. G. (2013). Best Environmental Management Practice in the Tourism Sector. JRC Scientific and Policy Report on. European Union. Viitattu, 16, 2015.

Susskind, A. M. (2014). Guests' Reactions to In-Room Sustainability Initiatives. Cornell Hospitality Quarterly, 55(3), 228-238.

Teng, C. C., \& Chang, J. H. (2014). Effects of temporal distance and related strategies on enhancing customer participation intention for hotel eco-friendly programs. International Journal of Hospitality Management, 40, 92-99.

Thaler, R. H., \& Sunstein, C. R. (2008). Nudge. Improving decisions about health, wealth and happiness. London, UK: Penguin.

Trope, Y., \& Liberman, N. (2003). Temporal construal. Psychological Review, 110(3), 403.

Trope, Y., \& Liberman, N. (2010). Construal-level theory of psychological distance. Psychological Review, 117(2), 440.

Tversky, A., \& Kahneman, D. (1981). The framing of decisions and the psychology of choice. Science, 211(4481), 453-458.

Van der Linden, S. (2015). Intrinsic motivation and pro-environmental behaviour. Nature Climate Change, 5(7), 612-613.

Villarino, J., \& Font, X. (2015). Sustainability marketing myopia: The lack of persuasiveness in sustainability communication. Journal of Vacation Marketing, 21(4), 326-335.

Warren, C., Becken, S., \& Coghlan, A. (2016). Using persuasive communication to cocreate behavioral change-engaging with guests to save resources at tourist accommodation facilities. Journal of Sustainable Tourism, 25(7), 935-954.

White, K., \& Simpson, B. (2013). When Do (and Don't) Normative Appeals Influence Sustainable Consumer Behaviors? Journal of Marketing, 77(2), 78-95.

White, K., MacDonnell, R., \& Dahl, D. W. (2011). It's the Mind-Set That Matters: The Role of Construal Level and Message Framing in Influencing Consumer 
Efficacy and Conservation Behaviors. Journal of Marketing Research, 48(3), 472-485.

WRAP (2011). The Composition of Waste Disposed of by the UK Hospitality Industry: WRAP.

WRAP (2015). Hotels: Taking Action on Waste: WRAP.

WRAP (2017). The Hospitality and Food Service Agreement Taking action on waste: WRAP.

Yüksel, A. (2017). A critique of "Response Bias" in the tourism, travel and hospitality research. Tourism Management, 59, 376-384.

Zhu, L., He, Y., Chen, Q., \& Hu, M. (2017). It's the thought that counts: The effects of construal level priming and donation proximity on consumer response to donation framing. Journal of Business Research, 76, 44-51. 
Table 1: Main contributions on prospect theory, construal level theory, and perceived self-efficacy

\begin{tabular}{|c|c|c|}
\hline Theory & Academic Papers & Key findings \\
\hline \multirow{4}{*}{$\begin{array}{l}\text { Prospect Theory } \\
\text { (loss/gain) }\end{array}$} & $\begin{array}{l}\text { Definition } \\
\text { (Tversky \& Kahneman 1981) }\end{array}$ & $\begin{array}{l}\text { The paper offers a conceptualization of prospect theory, which postulates that the } \\
\text { outcomes of decisions can be framed as either perceived losses (loss frame) or perceived } \\
\text { gains (gain frame). }\end{array}$ \\
\hline & $\begin{array}{l}\text { Loss-framed message } \\
\text { (Meyerowitz \& Chaiken } 1987 \text {; } \\
\text { Cheng et al. 2011) }\end{array}$ & $\begin{array}{l}\text { These papers suggest that loss-framed message, compared to gain-framed message, are } \\
\text { more persuasive in fostering intentions and behavior because of the tendency to } \\
\text { perceive negative information as more important, salient, and fear inducing. The empirical } \\
\text { evidences demonstrate that this effect can be detected in case of both health and } \\
\text { environmental behaviors, suggesting that loss-framed message produce more favorable } \\
\text { intentions to adopt the target behavior. }\end{array}$ \\
\hline & $\begin{array}{l}\text { Mixed Results } \\
\text { (Rothman et al. 1993; Meyers- } \\
\text { Levy \& Maheswaran, 2004) }\end{array}$ & $\begin{array}{l}\text { These empirical evidences suggest that the persuasiveness of loss or gain-framed } \\
\text { message changes according to different circumstances. Specifically, the papers suggest } \\
\text { that when people perceived a high level of involvement, environmental concern, and risk, } \\
\text { gain-framed message would work better than loss-framed message. On the contrary, in } \\
\text { case of low involvement, less environmental concern and low risk circumstances, loss- } \\
\text { framed message are more able to affect intentions and behaviors to avoid negative } \\
\text { consequences than positive frame. }\end{array}$ \\
\hline & $\begin{array}{l}\text { Loss-Gain Framing in } \\
\text { Tourism Literature } \\
\text { (Kim \& Kim, 2014; Blose et al. } \\
\text { 2015) }\end{array}$ & $\begin{array}{l}\text { Kim and Kim (2014) show that positive messages (gain-framed) are better able to affect } \\
\text { guests' pro-environmental behaviours (i.e., visit intentions and water and energy } \\
\text { saving). On the other hand, Blose et al. (2015) show that, compared to gain framed } \\
\text { messages, loss framed messages influence hotel guests' decision to engage in linen- } \\
\text { reuse programs. }\end{array}$ \\
\hline \multirow{2}{*}{$\begin{array}{l}\text { Construal Level } \\
\text { Theory } \\
\text { (concrete/abstract) }\end{array}$} & $\begin{array}{l}\text { Definition } \\
\text { (Liberman \& Trope 1998; } \\
\text { Trope \& Liberman 2003; } \\
\text { Trope \& Liberman 2010; } \\
\text { Liberman \& Trope 2008) }\end{array}$ & $\begin{array}{l}\text { Construal level theory (CLT) explains how psychological distance influences mental } \\
\text { representation, judgment, and choice. Individuals use concrete, low-level construals, to } \\
\text { represent near events and abstract, high-level construals, to represent distant events. }\end{array}$ \\
\hline & $\begin{array}{l}\text { CLT in sustainable } \\
\text { communication } \\
\text { (White et al. 2011; Lee \& Oh } \\
\text { 2014; Line et al. 2016; Teng \& } \\
\text { Chang 2014) }\end{array}$ & $\begin{array}{l}\text { These empirical evidences suggest that CLT can be a useful framework to investigate the } \\
\text { sustainability communication process. Specifically, the papers demonstrate that green } \\
\text { appeals are more effective when they match the individual's mindsets } \\
\text { (concrete/abstract). Moreover, some papers suggest the moderating role of CLT in } \\
\text { framing message, arguing that the effect of the message (loss vs. gain) can be } \\
\text { strengthened or weakened according to the level of construal (concrete/abstract). }\end{array}$ \\
\hline \multirow{3}{*}{$\begin{array}{l}\text { Perceived Self- } \\
\text { Efficacy }\end{array}$} & \begin{tabular}{|l} 
Definition \\
(Bandura 1998)
\end{tabular} & $\begin{array}{l}\text { According to social cognitive theory, perceived self-efficacy refers to "beliefs in one's } \\
\text { capabilities to mobilize the motivation, cognitive resources, and courses of action } \\
\text { needed to meet given situational demands" (p.624). }\end{array}$ \\
\hline & $\begin{array}{l}\text { Meyerowitz \& Chaiken } 1987 ; \\
\text { Abhyankar et al. } 2008\end{array}$ & $\begin{array}{l}\text { These papers provide evidence that in the health communication loss framed message } \\
\text { increase individuals' intentions and behaviors because of a greater perceived self- } \\
\text { efficacy. In these cases, people feel themselves to be capable to operate as active agents } \\
\text { of their own actions and that they possess the necessary skills to obtain certain } \\
\text { outcomes. }\end{array}$ \\
\hline & Morton et al. 2011 & $\begin{array}{l}\text { This paper supports the link between perceived gain-framed message and perceived self- } \\
\text { efficacy in the case of environemtal behaviour. However, looking at the results, this } \\
\text { effect is moderated by the level of uncertainty. }\end{array}$ \\
\hline
\end{tabular}


Table 2. Descriptive Statistics ( $n=360$ )

\begin{tabular}{llrc}
\hline Variable & Variable Description & Mean & \multicolumn{1}{c}{ St. Dev. } \\
\hline Treatment & 0 no treatment vs. 1 treatment & 0.83 & 0.500 \\
Loss & 0 gain-framed message vs. 1 loss-framed & 0.50 & 0.501 \\
& message & & \\
Concrete & 0 abstract vs. 1 concrete & 0.41 & 0.493 \\
Recycled/MaxPossible & 0 completely absence of recycling & 0.43 & 0.425 \\
Recycle & behavior, 1 maximum possible recycling & & \\
Business & behavior & & \\
Age & 0 leisure vs. 1 business & 0.44 & 0.498 \\
Gender & Age of guests & 42.36 & 9.738 \\
Group & 0 female vs. 1 male & 0.33 & 0.471 \\
East & 0 individual vs. 1 group & 0.61 & 0.489 \\
\hline
\end{tabular}

Table 3. Average recycling behaviour by condition

\begin{tabular}{lccl}
\hline Variable & Loss & Gain & $\begin{array}{l}\text { Test of } \\
\text { difference }\end{array}$ \\
\hline Abstract & 0.408 & 0.411 & $n . s$ \\
Concrete & 0.590 & 0.373 & $* * *$ \\
\hline$* * * p<0.01,{ }^{* *} p<0.05, * p<0.1$ &
\end{tabular}


Table 4. Regression analysis

\begin{tabular}{lc}
\hline $\begin{array}{l}\text { Dependent variable - } \\
\text { Variables }\end{array}$ & Relative recycling \\
\hline Loss & -0.00382 \\
& $(0.0631)$ \\
Concrete & -0.0434 \\
& $(0.0651)$ \\
LossXconcrete & $0.229^{* *}$ \\
& $(0.0896)$ \\
Business & -0.00452 \\
& $(0.0461)$ \\
Age & 0.000687 \\
& $(0.00235)$ \\
Female & $0.111^{* *}$ \\
& $(0.0484)$ \\
Group & 0.0256 \\
& $(0.0455)$ \\
East & 0.0373 \\
& $(0.0541)$ \\
Constant & $0.325^{* * *}$
\end{tabular}

$(0.118)$

Observations

360

Standard errors in parentheses

$* * * \mathrm{p}<0.01, * * \mathrm{p}<0.05, * \mathrm{p}<0.1$

292 clusters in customerid

Table 5: Recycling Intentions and Perceived Self-Efficacy by Condition

\begin{tabular}{|c|c|c|c|c|}
\hline & Perceived self-efficacy & Recycling Intentions & & \\
\hline Perceived self-efficacy & - & $0.309 * * *$ & & \\
\hline Loss-framed Message & 0.121 & -0.155 & & \\
\hline Concrete level of construal & 0.249 & - & & \\
\hline $\begin{array}{l}\text { Loss-framed Message X Concrete level } \\
\text { of construal }\end{array}$ & $2.808 * * *$ & - & & \\
\hline Gender & 0.067 & 0.204 & & \\
\hline Age & -0.006 & 0.001 & & \\
\hline \multicolumn{5}{|c|}{ Conditional Indirect Effects } \\
\hline Indirect Effect & $\begin{array}{c}\text { Construal level of the } \\
\text { message }\end{array}$ & Effect & $\begin{array}{c}\text { Lower Limit of } \\
\text { the } 95 \% \\
\text { Confidence } \\
\text { Interval }\end{array}$ & $\begin{array}{c}\text { Upper Limit of } \\
\text { the } 95 \% \\
\text { Confidence } \\
\text { Interval }\end{array}$ \\
\hline Perceived self-efficacy & $\begin{array}{l}0 \text {, that is abstract level of } \\
\text { construal }\end{array}$ & .0376 & -.0774 & .2055 \\
\hline Perceived self-efficacy & $\begin{array}{c}1 \text {, that is concrete level of } \\
\text { construal }\end{array}$ & .9068 & .2907 & 1.4945 \\
\hline
\end{tabular}




\section{Figure 1}

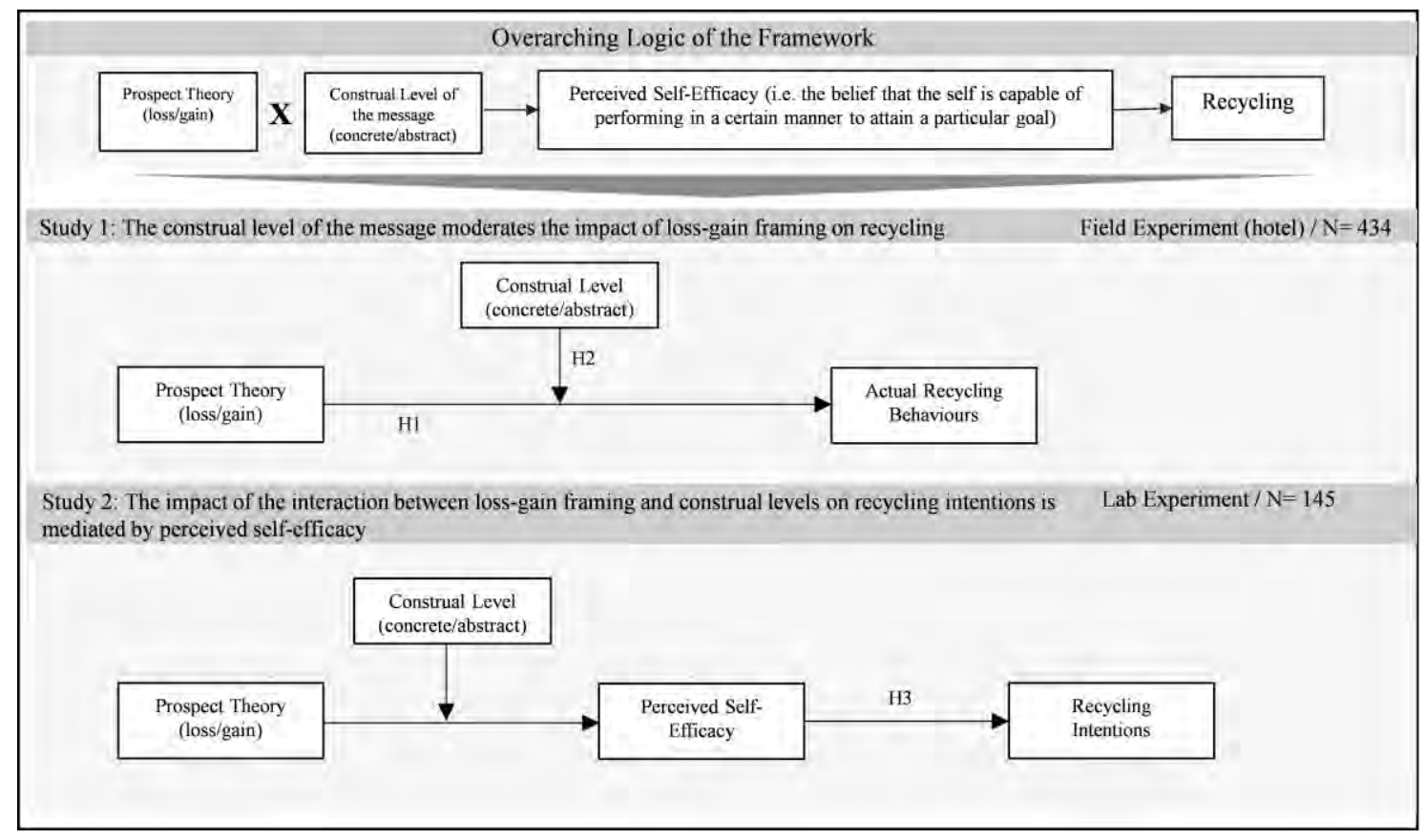


Figure 2 -Loss/abstract

Think about what we will lose if we don't recycle

By not recycling, we waste over 12.5 million tonnes of paper and cardboard

- the equivalent of 300 million trees every year in the UK alone.

By not recycling, we waste energy which results in more greenhouse gas emissions.

If we don't use materials more than once, we will not preserve our natural resources.

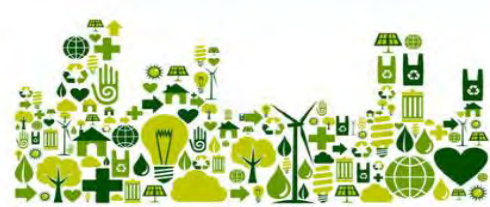

Think about reasons to make a difference

You can use the bins that you find in this room for recycling your waste. Recycling save the quality of our air, land and water resources.

Recycling preserve the health of our environment.

Recycling helps to reduce the pollution caused by waste.

Recycling reduces the need for raw materials.
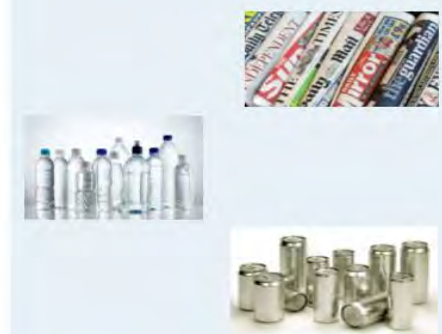
Figure 2 - Gain/abstract

Think about what we will gain if we recycle

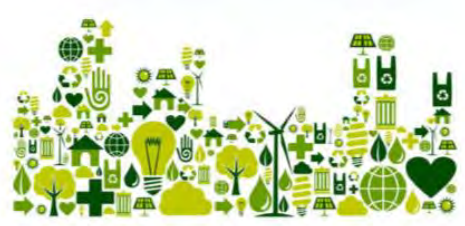

Think about reasons to make a difference

You can use the bins that you find in

this room for recycling your waste.

Recycling save the quality of our air, land and water resources.

Recycling preserve the health of our environment.

Recycling helps to reduce the pollution caused by waste.

Recycling reduces the need for raw materials.
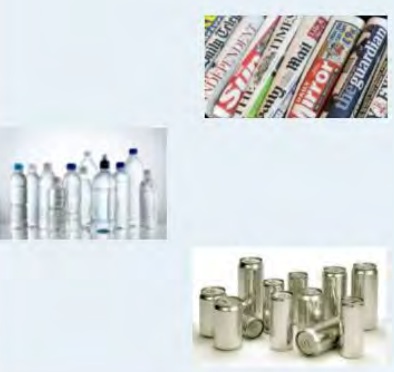
Figure 2 Gain-Concrete version

Think about what we will gain if we recycle
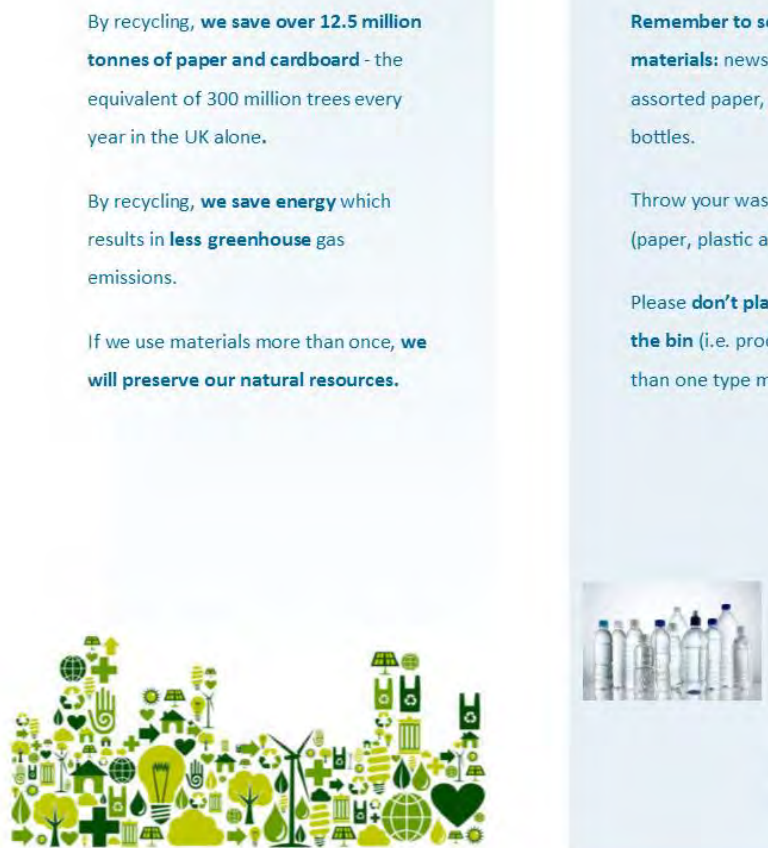

Think about ways to make a difference

You can use the bins that you find in this room for recycling your waste.

Remember to sort the different materials: newspapers, magazines and assorted paper, plastic containers and bottles.

Throw your waste into the specific bin (paper, plastic and/or glass).

Please don't place mixed material in the bin (i.e. products made with more than one type material).
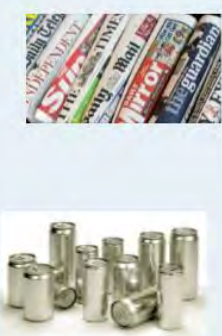
Figure 2 Loss-Concrete version

Think about what we will lose if we don't recycle

By not recycling, we waste over 12.5 million tonnes of paper and cardboard - the equivalent of 300 million trees every year in the UK alone.

By not recycling, we waste energy

which results in more greenhouse gas emissions.

If we don't use materials more than once, we will not preserve our natural resources.
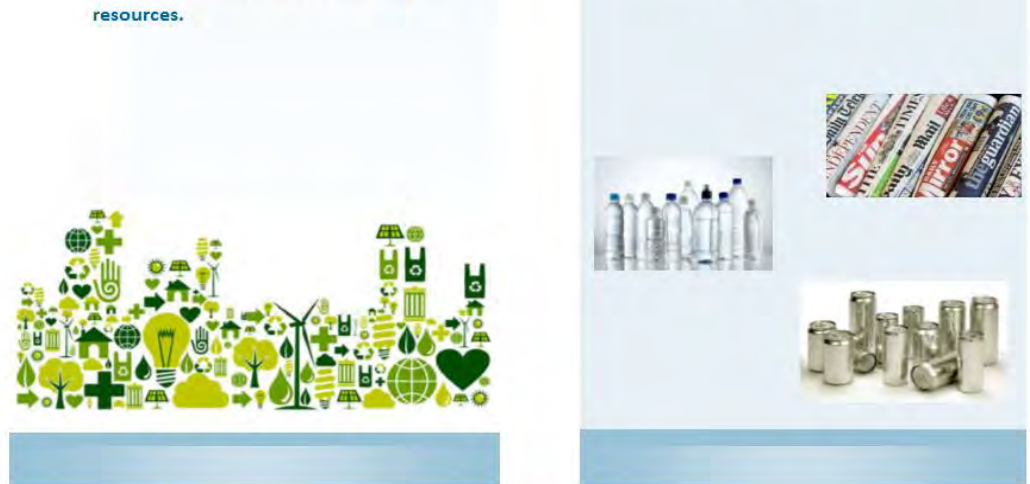

materials: newspapers, magazines and

assorted paper, plastic containers and bottles.

Throw your waste into the specific bin (paper, plastic and/or glass).

Please don't place mixed material in the bin (i.e. products made with more than one type material). 
Figure 3: Conditional indirect effects of loss-framed message on recycling intentions

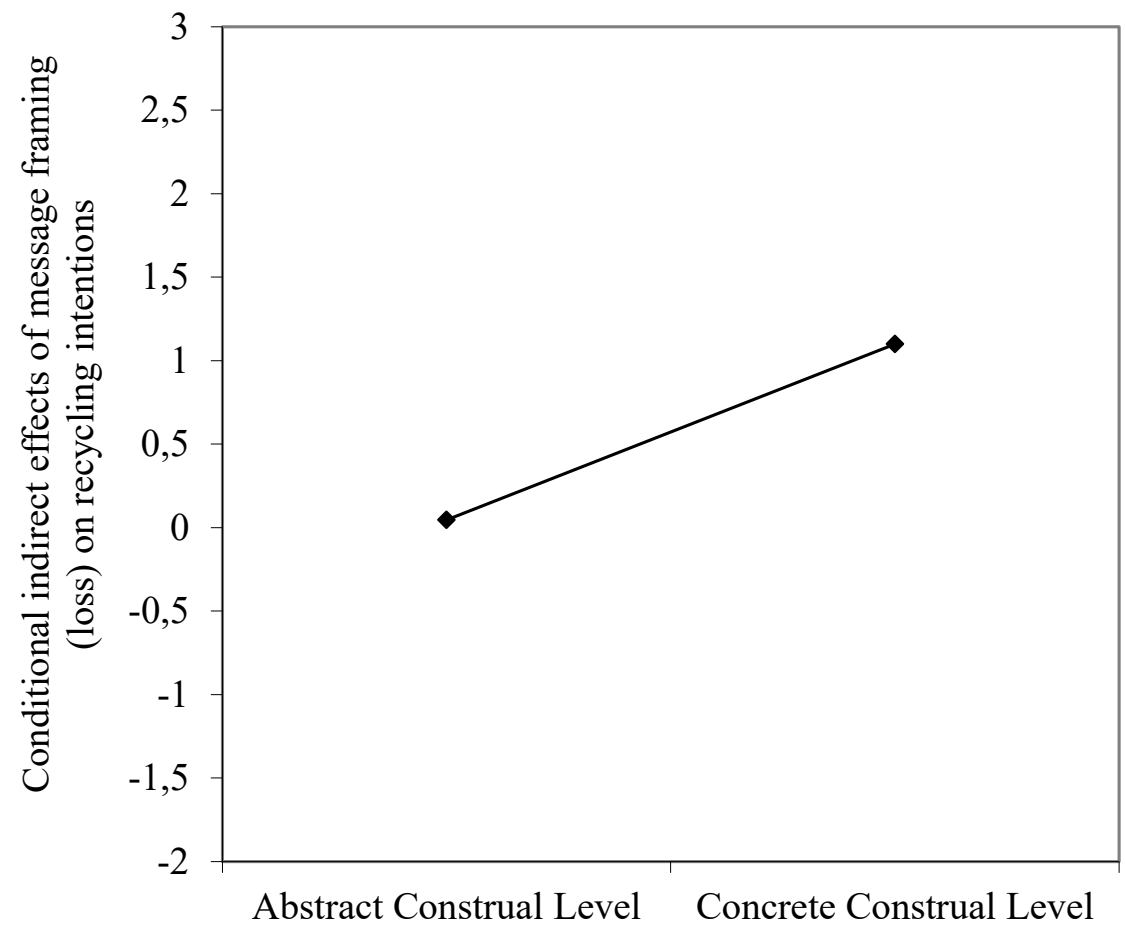

